\title{
Amidoxime Selective Adsorption for Uranyl and Transition Metals
}

\author{
Guilin Wei ${ }^{\mathrm{a}}$,Fangting $\mathrm{Chi}^{\mathrm{b}}$,PinglinGuo ${ }^{\mathrm{c}}$,Ziyue Gong,Fule Liu,TianliQiu
}

\author{
Fundamental Science on Nuclear Wastes and Environmental Safety Laboratory,Southwest \\ university of science and technology, Mianyang, 621010, China \\ a15284016123@163.com, ${ }^{b}$ chifangting@163.com, ${ }^{c 96419088 @ q q . c o m}$
}

\begin{abstract}
Keywords:Density functional theory;Designation of ligand structure; Bond lengths; thermodynamic parameters.

Abstract:Uranium is the most useful resource in nuclear reactor. But the land resource won't satisfy the nuclear reactor in the future. There still existsa large amountofuraniumin the seawater.The seawater environmenthas been simulated by Amsterdam Density Functional(ADF) forgetingan orderbetween uranyl $\left(\mathrm{UO}_{2}{ }^{2+}\right)$ and transtition metals under the amidoxime selective adsorpition.Amidoxime selective adsorption for uranyl $\left(\mathrm{UO}_{2}{ }^{2+}\right)$ and transition metalswas calculated.The results show that the order of different transition metals with amidoxime in the water environment is $\mathrm{Fe}(\mathrm{III})>\mathrm{Ni}(\mathrm{II})>\mathrm{Co}(\mathrm{II})>\mathrm{Cu}(\mathrm{II})>\mathrm{UO}_{2}(\mathrm{VI})$, based on the designation of ligand structure,bond lengths, the thermodynamic parameters, and the relation between frequency and absorption intensity.Maybe it means the transition metal combines with amidoxime than uranium easier.
\end{abstract}

\section{Introduction}

Nuclear power has advantages in many aspects as a new energy, such as high energy density, clean, low carbon. The total 440 nuclear reactors can provideabout $17 \%$ of the electricity for the whole world.Uranium ore is the most crucialsubstancefor unclear power. The word organization for economic cooperation and development estimates global land storage capacity isabout6.3 million tons of uranium ore ${ }^{[1]}$.As the expending of uranium, the uraniumjust can satisfy future human development a century. Land of uranium reserves won't satisfy people's needs for future nuclear power.Looking for the new sources of uranium become the various countries' research hot spot. Vast uraniumdissolve in Seawaterabout 4.5 billion tons, are one thousand times of the land reserves ${ }^{[2]}$. If we can make full use of uranium, then we can effectively solve the problem of lack of uranium, meet the needs of nuclear reactor in the future ${ }^{[3]}$, can effectively reduce exhaust emissions and the destruction of natural environment, and it is also benefit to human.

Nowadays so many countries like Japan, American and India has studiedhow to extracturanium from seawater. Total uranium content inseawater is high, but it's concentration for only $3-3.3 \mu \mathrm{g} / \mathrm{ml}$ (3-3.3ppb).Betweenthe $\mathrm{pH} 8.0$ to 8.3, low concentration of uranium is mainly in the form of carbonate ion complex, and the seawater also dissolved $\mathrm{UO}_{2}(\mathrm{OH})_{3}{ }^{-}, \mathrm{UO}_{2}\left(\mathrm{CO}_{3}\right)_{2}{ }^{2-}, \mathrm{UO}_{2}{ }^{2+}, \mathrm{UO}_{2}(\mathrm{OH})^{+}$and $\mathrm{UO}_{2}(\mathrm{OH})_{2}$. There still coexist other metal ions, some concentration is much higher than uranium concentration (such as sodium, potassium, calcium, magnesium, strontium, etc. ${ }^{[4]}$,some ions'concentration is close to the concentration of uranium (such as iron, aluminum, zinc, nickel, vanadium, molybdenum, etc.). So for the preparation of high selectivity, thehigh efficiency adsorption is the key to realize large-scale collect uranium in seawater. Up to now, there are 200 kinds of macromolecule.Amidoxime based polymer adsorbent of uranium ion in the water environment (uranium) and reflects the better performance of extraction ${ }^{[5]}$. Because of the complexity of seawater environment, amidoximeadsorbents and the adsorption mechanism of uranium in seawater has been research hot spots.But it is also difficult to research it. The reason is that there are so many ions in seawater, like transition metals and other mixtures. So in this area, a good adsorbent is vitally important. Germany Julich nuclear research center studiedtogether amidoximecrosslinked polypropylene resin adsorbent for seawater uraniumin the early $1980 \mathrm{~s}^{[6]}$, oxime proposed accompanying amine ligand exist two configurations: open-loop and closed-loop. They predicted that the closed loop type oxime together amine ligand wastridentate ligand, and maybe uraniumwas better than carbonate ions in coordination stability. The Berkeleynational laboratory,LingfengRao group 
tested the reaction process through the experiment of thermodynamic parameters ${ }^{[7]}$, and combined with density functional theory verified the oxime together amine ligand to tridentate ligand with uranyl ions to form stable complexes. The studies have shown that glutaric imide and Fe(III) formed complexes with glutaricamidoxime and uranium complexes generated more stable ${ }^{[8]}$.Amidoxime sorbents extract uranium in seawater has important value of research and application, and oxime together amine ligand coordination mechanism of uranium ion and selective strength remains controversial. Then find a best structure of amidoxime become more and more crucial.

In this paper, the same environment like seawater has been simulated in ADF. Amidoxime selective adsorption for uranyl $\left(\mathrm{UO}_{2}{ }^{2+}\right)$ and transition metals were calculated as well. The purpose is to get the best optimized structures and get the result of stability of sorting between the transition metals and the uranyl.

\section{Computational details}

Geometry optimization, bond lengths and frequency were calculated by the ADF software.On the choice of parameter, we choose GGA: PBE in XC potential in SCF, default in XC energy after SCF, Scalar in Relativity (ZORA), TZP for the Basis set, medium in frozen core and the integration is teVelde 10. This is the gas environment parameter, thenwe set the same parameter in water solvent but need to add the solvation as water and set the solvation method as COSMO, klamt in Default radii. The geometries of all complexes were fully optimized, followed by harmonic vibrational energy contribution. The results about $\Delta \mathrm{S}, \Delta \mathrm{U}, \Delta \mathrm{E}_{\text {zero-point energy }}, \Delta \mathrm{E}_{\text {bonding- energy }}$ can give the best steady construction.$\Delta$ Sis Entropy change which is to discribe a system of chaos, and with the $\Delta \mathrm{S}$ increase, the chaos will increase as well. It's a standard to judge the direction of a spontaneous reaction. $\Delta U$ is Enthalpy change which is to describe the difference between reactants and products. $\Delta \mathrm{E}_{\text {zero-point energy }}$ is a kind of energy at the $0{ }^{\circ} \mathrm{C}$, and the $\Delta \mathrm{E}$ bonding-energy is the bonding energy.

\section{Results and discussion}

\subsection{Structures of the complexes.}

Fig. 1 shows the calculation results of structures for the complex.It can be seen that the structure are symmetric.Table 1, 2 shows the bonding length between different atoms. Table 3, 4 shows the bonding length between the transition metals and Oxygen, and the bonding length between transition metals and Nitrogen.The uranyl and transition metals have two kinds of combination way with amidoxime. The first combination way is $\mathrm{Cis}$ which is rotational symmetry, and another is Transwhich is central symmetry ${ }^{[9]}$. In the result, the bond lengthshave connected with bond energy. The longer length structure will be more unstable. The bonding energy will become low and the bonding region is insecure. So from this point, the molecule's stability can be judge easily. From Table 1, the $\mathrm{C}-\mathrm{C}, \mathrm{N}-\mathrm{O}, \mathrm{C}-\mathrm{N}$ and $\mathrm{C}=\mathrm{N}$ are similar in different environment or in different symmetrical structure. But the difference still existed. The important parts are existed in Table 2.From Table 2, the distance between metals and ligating atoms can make an easy comparison. Fe (II)has the shortest bonding length with oxygen and nitrogen. The second is $\mathrm{Ni}$ (II), and then $\mathrm{Co}$ (II), $\mathrm{Cu}$ (II). The last one is $\mathrm{UO}_{2}$ (II). So the result of stability of sorting: $\mathrm{Fe}$ (III) $>\mathrm{Ni}$ (II) $>\mathrm{Co}$ (II) $>\mathrm{Cu}$ (II) $>\mathrm{UO}_{2}$ (II).

The nature of stability can be explained by the theoryof HSAB.HSAB was mainly usedto discuss themetal ion complexes system; predict response direction; stability prediction complexes; reasonable explanation goldschmidt rules. Itdepends on the nature of the acid and alkaline which can be divided into two kinds of the theory of hard and soft. This theory is suitable for many kinds of chemical phenomena, such as acid-base reaction, the effect between mental and ligand, complex ion form, the formation of covalent of covalent and ionic bonds.Hard acid priority with hard base, soft acid combined with soft base priority. Due to this ability, different ions can be divided into different groups. For example:hard acid, border acid, hard base, soft acid, border base, soft base. Fe(III) is the strong acid because of the small volume, high positive charge number, and can be the center of the low polarizability, $\mathrm{Cu}(\mathrm{II}), \mathrm{Co}(\mathrm{VI})$ and $\mathrm{Ni}(\mathrm{II})$ are the Border acids .Border acids is a kind of acids which can react with strong and weak acids, and have the same stability to adsorb the ions.It can be 
conclude thatthe sorting in transition metals as follows: $\mathrm{Fe}(\mathrm{III})>\mathrm{Ni}(\mathrm{II})>\mathrm{Co}(\mathrm{II})>\mathrm{Cu}(\mathrm{II})>\mathrm{UO}_{2}(\mathrm{VI})$.

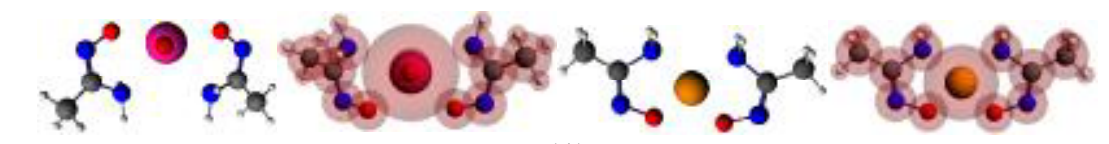

(1)

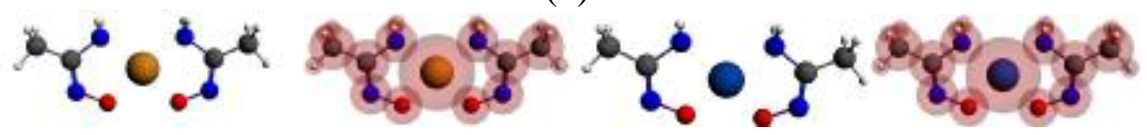

(2)

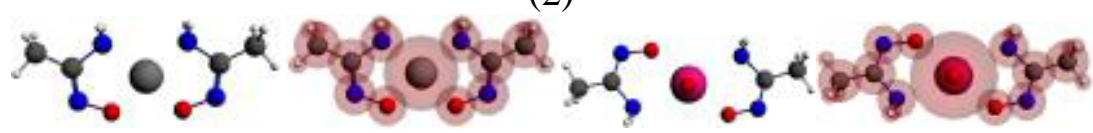

(3)

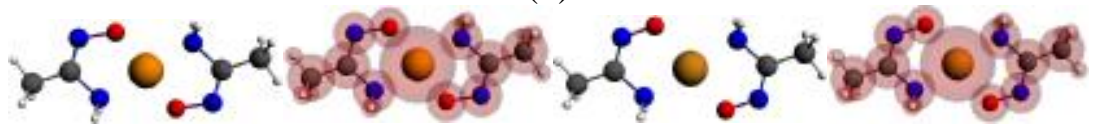

(4)

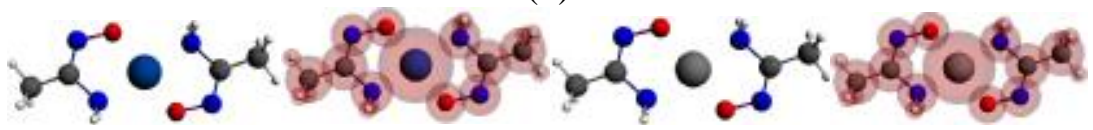

(5)

Figure 1Designation of ligand structures

Figure 1 Structure ofcomplexes center atom (1) $\mathrm{UO}_{2}=$ uranyl, (2) $\mathrm{Fe}=\mathrm{Iron},(3) \mathrm{Co}=\mathrm{Cobalt}$, (4) $\mathrm{Ni}=$

Nickel, (5) $\mathrm{Cu}=$ Copper, (Color code: oxygen=red, carbon=grey, Nickel=light grey, Cobalt=blue, Iron=deep yellow, Copper=yellow, Uranyl=amaranth)

Table 1Optimized C-C, N-O, C-N and C=N bond lengths $(\AA)$ for optimize complexes of the metals ions in $C$ is structure.

\begin{tabular}{ccccccccc}
\hline Metal(M) & \multicolumn{9}{c}{ Cis } \\
\cline { 2 - 9 } & \multicolumn{9}{c}{ Gas } & \multicolumn{7}{c}{ liquid } \\
\cline { 2 - 9 } & C-C & N-O & C-N & C=N & C-C & N-O & C-N & C=N \\
\hline $\mathrm{UO}_{2}^{2+}$ & 1.491 & 1.381 & 1.452 & 1.289 & 1.491 & 1.401 & 1.441 & 1.293 \\
$\mathrm{Fe}^{3+}$ & 1.486 & 1.359 & 1.490 & 1.280 & 1.484 & 1.359 & 1.490 & 1.282 \\
$\mathrm{Co}^{2+}$ & 1.493 & 1.349 & 1.472 & 1.290 & 1.493 & 1.369 & 1.468 & 1.289 \\
$\mathrm{Ni}^{2+}$ & 1.492 & 1.343 & 1.472 & 1.290 & 1.492 & 1.368 & 1.464 & 1.289 \\
$\mathrm{Cu}^{2+}$ & 1.491 & 1.328 & 1.462 & 1.298 & 1.487 & 1.358 & 1.456 & 1.324 \\
\hline
\end{tabular}

Table 2 Optimized C-C, N-O, C-N and C=N bond lengths $(\AA)$ for optimize complexes of the metals ions in Trans structure.

\begin{tabular}{|c|c|c|c|c|c|c|c|c|}
\hline \multirow[t]{3}{*}{ Metal(M) } & \multicolumn{8}{|c|}{ Trans } \\
\hline & \multicolumn{4}{|c|}{ Gas } & \multicolumn{4}{|c|}{ liquid } \\
\hline & $\mathrm{C}-\mathrm{C}$ & $\mathrm{N}-\mathrm{O}$ & C-N & $\mathrm{C}=\mathrm{N}$ & C-C & $\mathrm{N}-\mathrm{O}$ & C-N & $\mathrm{C}=\mathrm{N}$ \\
\hline $\mathrm{UO}_{2}{ }^{2+}$ & 1.494 & 1.353 & 1.471 & 1.289 & 1.493 & 1.370 & 1.463 & 1.289 \\
\hline $\mathrm{Fe}^{3+}$ & 1.486 & 1.369 & 1.486 & 1.282 & 1.484 & 1.384 & 1.473 & 1.283 \\
\hline $\mathrm{Co}^{2+}$ & 1.493 & 1.372 & 1.470 & 1.287 & 1.493 & 1.389 & 1.464 & 1.287 \\
\hline $\mathrm{Ni}^{2+}$ & 1.493 & 1.360 & 1.470 & 1.289 & 1.492 & 1.377 & 1.464 & 1.287 \\
\hline $\mathrm{Cu}^{2+}$ & 1.493 & 1.310 & 1.469 & 1.288 & 1.491 & 1.325 & 1.465 & 1.287 \\
\hline
\end{tabular}


Table 3 The Optimized metal-ligand bond lengths $(\AA)$ in Cisstructure.

\begin{tabular}{|c|c|c|c|c|}
\hline \multirow[t]{3}{*}{$\operatorname{Metal}(\mathrm{M})$} & \multicolumn{2}{|c|}{ Cis } & \multicolumn{2}{|c|}{ Trans } \\
\hline & Gas & liquid & Gas & liquid \\
\hline & \multicolumn{2}{|c|}{$\mathrm{M}-\mathrm{O}$} & \multicolumn{2}{|c|}{$\mathrm{M}-\mathrm{O}$} \\
\hline $\mathrm{UO}_{2}{ }^{2+}$ & 2.223 & 2.222 & 2.215 & 2.214 \\
\hline $\mathrm{Fe}^{3+}$ & 1.804 & 1.814 & 1.835 & 1.846 \\
\hline $\mathrm{Co}^{2+}$ & 1.925 & 1.927 & 1.889 & 1.897 \\
\hline $\mathrm{Ni}^{2+}$ & 1.896 & 1.900 & 1.897 & 1.902 \\
\hline $\mathrm{Cu}^{2+}$ & 1.978 & 1.956 & 2.062 & 2.066 \\
\hline
\end{tabular}

Table 4 The Optimized metal-ligand bond lengths $(\AA)$ in Transstructure.

\begin{tabular}{|c|c|c|c|c|}
\hline \multirow[t]{3}{*}{$\operatorname{Metal}(\mathrm{M})$} & \multicolumn{2}{|c|}{ Cis } & \multicolumn{2}{|c|}{ Trans } \\
\hline & Gas & liquid & Gas & liquid \\
\hline & \multicolumn{2}{|c|}{ M-N } & \multicolumn{2}{|c|}{ M-N } \\
\hline $\mathrm{UO}_{2}{ }^{2+}$ & 2.695 & 2.651 & 2.666 & 2.640 \\
\hline $\mathrm{Fe}^{3+}$ & 2.091 & 2.043 & 2.030 & 2.007 \\
\hline $\mathrm{Co}^{2+}$ & 2.109 & 2.074 & 2.051 & 2.049 \\
\hline $\mathrm{Ni}^{2+}$ & 2.056 & 2.026 & 1.996 & 1.995 \\
\hline $\mathrm{Cu}^{2+}$ & 2.097 & 2.073 & 2.048 & 2.048 \\
\hline
\end{tabular}

\subsection{The thermodynamic parameters}

The thermodynamic parameters' results consist of $S, U, E_{\text {zero-point energy }}, E_{\text {bonding- energy. And we use this }}$ data to calculate $\Delta \mathrm{G}$ which is the gist to prove the best steady construction. $\Delta \mathrm{G}(\mathrm{Kcal} / \mathrm{mol})$ is standard to judge nice or nasty absorbent for amidoxime and metal ions. We can't use the datas because of the negative frequency until the frequency is positive. The negative frequency means the structure is not the optimized result And it is found that the final results are almost the same whatever in gas or in water environment. So we guess that maybe there is no effect with the environment. Then the most significant step is calculate $\Delta \mathrm{G}$ to make sure the final construction we need.But the ADF cannot calculate the single ion. The single ion's thermodynamic parameters can't be calculated. Then a new ideal come out, calculate $\mathrm{M}\left(\mathrm{H}_{2} \mathrm{O}\right)_{4}{ }^{\mathrm{x}+}$ and use the formula 1:

$$
\mathrm{M}\left(\mathrm{H}_{2} \mathrm{O}\right)_{4}^{x+}+2 X A W=M(X A W)_{2}^{y+}+4 \mathrm{H}_{2} \mathrm{O}
$$

And then the single ion energy can come out easily.

First, the nRT have been calculated. $\triangle \mathrm{PV}$ can be calculated as soon. For the same way to calculate $\Delta \mathrm{U}, \Delta \mathrm{E}_{\text {zero-point energy }}$ and $\Delta \mathrm{E}$ bonding- energy. From theformula 2 can get the $\Delta \mathrm{H} . \Delta \mathrm{H}$ represents enthalpy to calculate $\Delta \mathrm{G}$. And then from the formula $3, \Delta \mathrm{G}$ calculated from the equation.

$$
\begin{gathered}
\Delta H=\Delta U+\Delta E_{\text {zreo-point energy }}+\Delta E_{\text {bonding-energy }}(2) \\
\Delta G=\Delta H-T \times \Delta S
\end{gathered}
$$

A large variation in complexation energies is apparent from the table. And from Table 5 andTable 6 , these are all negative number.The final solution $\Delta$ Gare all close, this means the reaction can react by itself. The greater negative number, the reaction can be react easily. But the real reaction is the seawater.So finally, we can get the best stable construction. From the table, the sorting in different

\begin{tabular}{|c|c|c|}
\hline \multirow[t]{3}{*}{$\operatorname{Metal}(\mathrm{M})$} & \multicolumn{2}{|c|}{$\Delta \mathrm{G}$} \\
\hline & \multicolumn{2}{|c|}{ Cis } \\
\hline & Gas & Liquid \\
\hline$\left[\mathrm{UO}_{2}\left(\mathrm{C}_{2} \mathrm{H}_{5} \mathrm{~N}_{2} \mathrm{O}\right)_{2}\right]$ & -564.094 & -151.545 \\
\hline$\left[\mathrm{Fe}\left(\mathrm{C}_{2} \mathrm{H}_{5} \mathrm{~N}_{2} \mathrm{O}\right)_{2}\right]^{+}$ & -290.053 & -240.032 \\
\hline$\left[\mathrm{Co}\left(\mathrm{C}_{2} \mathrm{H}_{5} \mathrm{~N}_{2} \mathrm{O}\right)_{2}\right]$ & -231.286 & -143.804 \\
\hline$\left[\mathrm{Ni}\left(\mathrm{C}_{2} \mathrm{H}_{5} \mathrm{~N}_{2} \mathrm{O}\right)_{2}\right]$ & -244.799 & -155.870 \\
\hline$\left[\mathrm{Cu}\left(\mathrm{C}_{2} \mathrm{H}_{5} \mathrm{~N}_{2} \mathrm{O}\right)_{2}\right]$ & -274.386 & -179.030 \\
\hline
\end{tabular}
transition metals and in the water environment is $\mathrm{Fe}(\mathrm{III})>\mathrm{Ni}(\mathrm{II})>\mathrm{Co}$ (II) $>\mathrm{Cu}$ (II) $>\mathrm{UO}_{2}$ (VI).

Table 5Optimized structure's energy for the transition metals in Cisstructure. 
Table 6 Optimized structure's energy for the transition metals in Transstructure.

\begin{tabular}{ccc}
\hline Metal $(\mathrm{M})$ & \multicolumn{3}{c}{$\Delta \mathrm{G}$} \\
\cline { 2 - 3 } & $\mathrm{Gas}$ & Trans \\
\cline { 2 - 3 } & -560.477 & Liquid \\
\hline$\left[\mathrm{UO}_{2}\left(\mathrm{C}_{2} \mathrm{H}_{5} \mathrm{~N}_{2} \mathrm{O}\right)_{2}\right]$ & -292.729 & -143.401 \\
{$\left[\mathrm{Fe}\left(\mathrm{C}_{2} \mathrm{H}_{5} \mathrm{~N}_{2} \mathrm{O}\right)_{2}\right]^{+}$} & -245.404 & -237.471 \\
{$\left[\mathrm{Co}\left(\mathrm{C}_{2} \mathrm{H}_{5} \mathrm{~N}_{2} \mathrm{O}\right)_{2}\right]$} & -255.761 & -150.900 \\
{$\left[\mathrm{Ni}\left(\mathrm{C}_{2} \mathrm{H}_{5} \mathrm{~N}_{2} \mathrm{O}\right)_{2}\right]$} & -279.226 & -144.42 \\
{$\left[\mathrm{Cu}\left(\mathrm{C}_{2} \mathrm{H}_{5} \mathrm{~N}_{2} \mathrm{O}\right)_{2}\right]$} & & -156.347 \\
\hline
\end{tabular}

\subsection{The analysis of Absorption density and Frequency}

For this part, figure 2 represents the relationship of Frequency and Absorption Intensity. First is Cis structures in Gas environment, next is Cis structures in water environment, Trans structures in Gas and water environment. And from the Figure 2, we found that the frequency's data in a large range. So the pattern can't analysis easily. From Chemistry's knowledge, we know that with the electrons transfer the energy will have a change. The more electrons, the energy will rise more. And the energy will have an effect on the M-X bonding length. So the rule is evident, it means the high-energy corresponding short bonding length, the low-energy corresponding long bonding length. From the results in the ADF, we found every structures' most short M-X bonding length's frequency was between $1000 \mathrm{~cm}^{-1}$ to $1250 \mathrm{~cm}^{-1}$. Figure 3 has been magnified between the ranges of $1000-1250 \mathrm{~cm}^{-1}$. The first is $C i s$ structures in Gas environment, next is Cis structures in water environment, Trans structures in Gas environment.
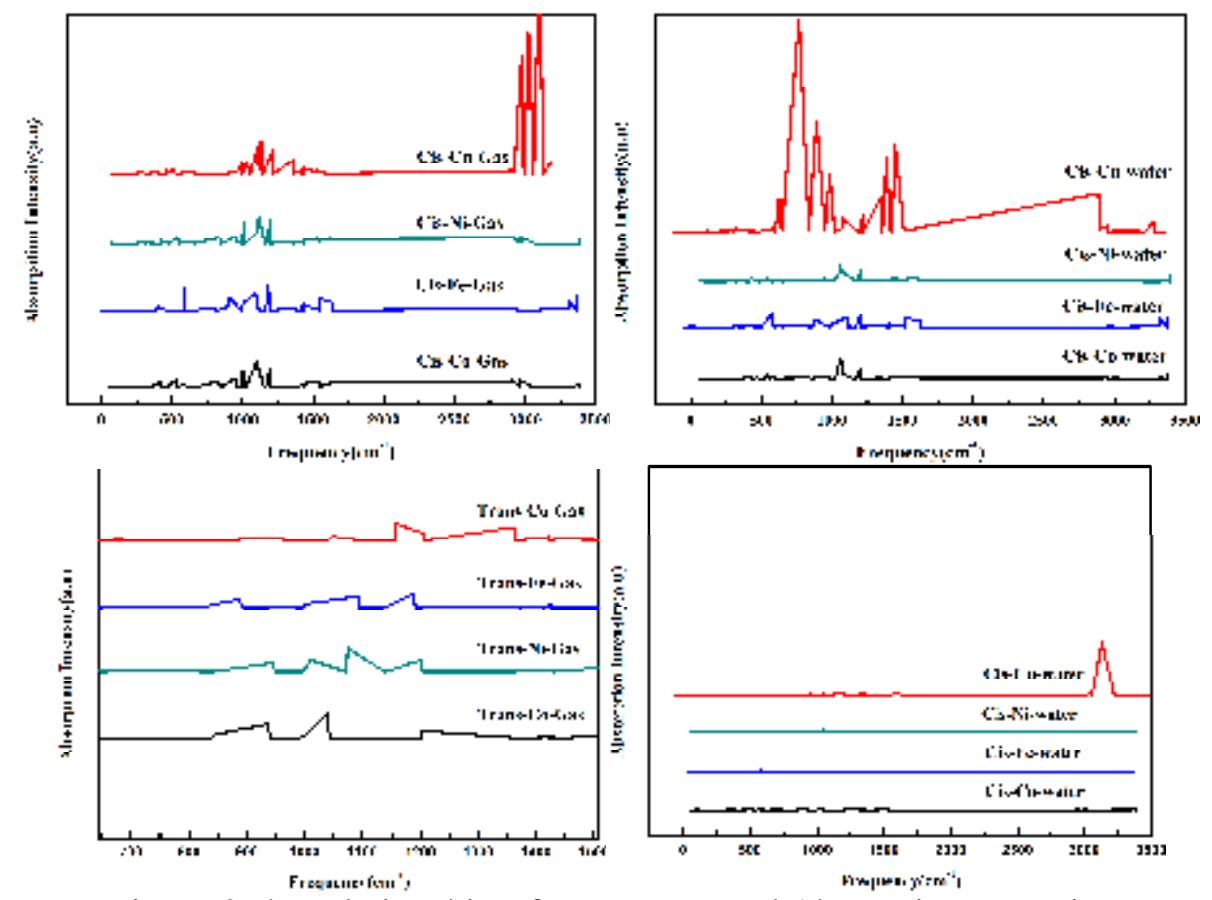

Figure 2The relationship of Frequency and Absorption Intensity

Figure 3 shows the relationship of Frequency and Absorption Intensity. From Figure 3, with the frequency's rise, the Absorption Intensity rises for a while at the beginning, then the Intensity fall until it became stabilization in the end. From the picture, Fe is the first to get the highest Intensity, so $\mathrm{Fe}$ is the easiest metal to combine with oxime. The second is $\mathrm{Co}$, then $\mathrm{Ni}$, and the final is $\mathrm{Cu}$. But the result was difficult to see the rule with $\mathrm{UO}_{2}(\mathrm{VI})$. The $\mathrm{UO}_{2}(\mathrm{VI})$. needs a farther exploration. And we just can get the transition metals'sorting is $\mathrm{Fe}($ III $)>\mathrm{Co}$ (II) $>\mathrm{Ni}$ (III) $>\mathrm{Cu}$ (II). 

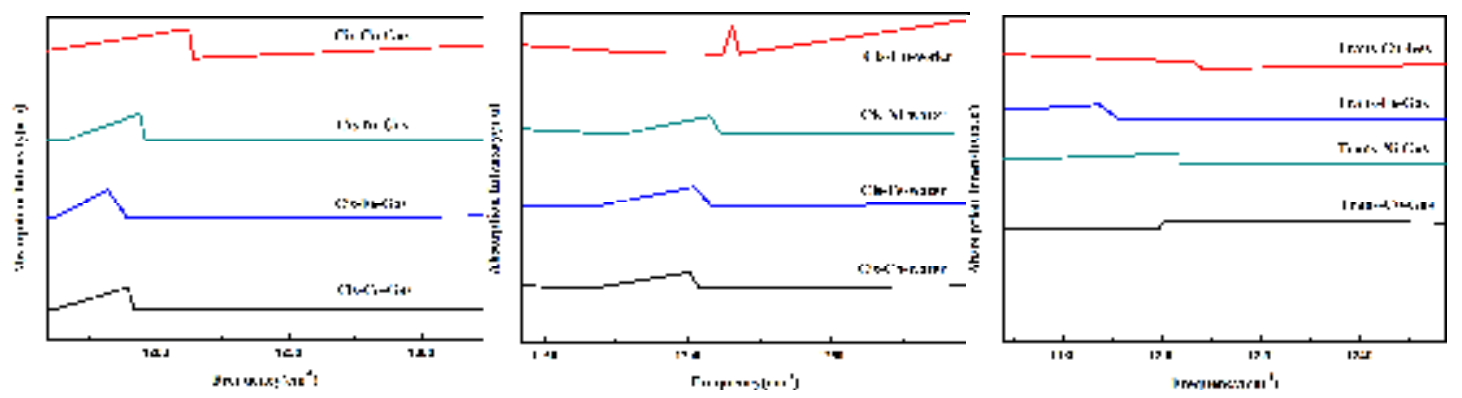

Figure 3The relationship of Frequency and Absorption Intensity

\section{Conclusions}

In this work, we calculated theAmidoxime selective adsorption for $\mathrm{UO}_{2}{ }^{2+}$ and transition metals. From the analysis of the bonding and thermodynamic parameters, we found that the transition metals combined with $\mathrm{UO}_{2}{ }^{2+}$ in water environment easier. We also got the same result in the Absorption Intensity and Frequency analyzed.But in the frequency range between $1000 \mathrm{~cm}^{-1}$ to $1250 \mathrm{~cm}^{-1}$, the regular result is similar with the result of other analysis. At the optimization structures, the final structures are symmetry. And from the resultswe can know that when the geometry optimization calculated finished, the construction has change into a more symmetrical structure. Of course, we have calculatedthe different environment in the gas and water environment. That is just to make the data become more convincing. In the water environment, the results are almost same with the gas environment. But there still have some difference between the two environments. I guess that maybe the $\mathrm{UO}_{2}{ }^{2+}$ and the transition metals have another from. Finally, the sorting is $\mathrm{Fe}(\mathrm{III})>\mathrm{Co}(\mathrm{II})>\mathrm{Ni}(\mathrm{III})>\mathrm{Cu}(\mathrm{II})>\mathrm{UO}_{2}$ (VI). But this time we just use the computer to calculate the single result. In the future, we will do the experiment to prove the results.

\section{References}

[1] Hill DJ. Nuclear energy for the future [J]. Nature Materials, 7, 680-682.(2008)

[2] R V Davies, Dr J Kennedy, R W Mcilroy, Dr R Spence and K M Hill. Extraction of uranium from sea water. Nature, 203, 1110-1115.(1964)

[3] Rao, L. Recent International R\&D Activities in the Extraction of Uranium from Seawater. In LBNL-4034E. LawrenceBerkeley National Laboratory, Berkeley, CA, USA.(2011)

[4] Jungseung Kim, Costas Tsouris, Richard T. Mayes et al. Recovery of uranium from seawater: a review of current status and future research needs. Separation Science and technology, 48: 367-387, (2013)

[5] Sinisa Vukovic, Lori A. Watson, Sung Ok Kang, Radu Custelcean, and Benjamin P. Hay. How amidoximate binds the uranyl cation, Inorg. Chem., 51, 3855-3859.(2012)

[6] Astheimer L, et al. Sep. Sci. Technol., 18, 307-339.(1983)

[7] GuoxinTian, SimonJTeat, ZhiyongZhang, and LinfengRao. Sequestering uranium from seawater: binding strength and modes of uranyl complexes with glutarimidedioxime.(2013)

[8] Xiaoqi Sun, Chao Xu, Guoxin Tian, and Linfeng Rao. Complexation of glutarimidedioxime with $\mathrm{Fe}$ (III), $\mathrm{Cu}$ (II), $\mathrm{Pb}$ (II), and $\mathrm{Ni}$ (II), the competing ions for the sequestration of U (VI) from seawater. Dalton Trans, , 42, 14621-14627.(2013)

[9] Metal ion complexes of thioformin: A density functional studyOriginal Research Article

[10]Polyhedron, Volume 26, Issue 18, Pages 5301-5308, 20 November (2007) 